\title{
Serum progranulin/tumor necrosis factor-a ratio as independent predictor of systolic blood pressure in overweight hypertensive patients: a cross-sectional study
}

Jasmine Kaur ${ }^{1}$, Supriya Mukheja ${ }^{1}$, Sudhir Varma ${ }^{2}$, Harpreet Singh Kalra ${ }^{2}$, Bipanjeet Singh Khosa ${ }^{3}$ and Kanchan Vohra ${ }^{1 *}$ (D)

\begin{abstract}
Background: Vascular inflammation plays a key role in the progression of hypertension. Progranulin (PGRN), an anti-inflammatory growth factor, mediated inhibition of tumor necrosis factor-a (TNF-a), a pleiotropic cytokine, activity has been well-established. Despite the role of chronic low-grade inflammation in hypertension, serum levels of PGRN and PGRN/TNF-a ratio and, their association with systolic and diastolic blood pressure has not been determined in hypertensive patients till now. This study aims to find and correlate the serum levels of proinflammatory cytokine (TNF-a), anti-inflammatory growth factor (PGRN), and PGRN/TNF-a ratio with the blood pressure in systolic-diastolic hypertension (SDH) and isolated systolic hypertension (ISH) patients.

Results: A cross-sectional study was conducted on SDH patients (mean age, $52.95 \pm 12.6$ years; male/female (M/F) number $=15 / 10)$ and ISH patients (mean age, $55.80 \pm 9.40$ years; M/F number $=12 / 13)(n=25$ each). Twenty-five age and body mass index (BMI)-matched healthy subjects (mean age, $56.00 \pm 8.55$ years; male/female number $=$ 11/14) were considered as control. All patients and healthy subjects were overweight (BMl, $\left.25-30 \mathrm{~kg} / \mathrm{m}^{2}\right)$. Overnight fasting blood samples of subjects were taken and levels of PGRN and TNF-a were measured using ELISA diagnostic kits. PGRN and TNF-a levels were found significantly high, whereas PGRN/TNF ratio was found very low, in SDH and ISH patients as compared to healthy subjects. Reduced PGRN/TNF-a ratio and pulse pressure were found as independent predictors of SBP both in SDH and ISH patients.

Conclusions: Findings of elevated PGRN levels in response to raised TNF-a levels depict the counter regulation by PGRN to neutralize TNF- $a$. Findings of reduced PGRN/TNF ratio, and it being an independent predictor of SBP, ascertain the key role of imbalance in pro- and anti-inflammatory environment in hypertension. Thus, it strengthens the cross-link between the concept of immunity-adiposity-inflammation-blood pressure, a vicious network. Further, this cross-link of SBP and progranulin must be explored in longitudinal studies. New researches should be focused not only on impact of pro-inflammatory environment rather to find on a balance between pro- and antiinflammatory status, so that new target sites could be explored for therapeutic management of hypertension.
\end{abstract}

Keywords: Progranulin, Tumor necrosis factor-a, Progranulin/tumor necrosis factor-a ratio, Systolic-diastolic hypertension, Isolated systolic hypertension, Independent predictor, Systolic blood pressure

\footnotetext{
* Correspondence: kanchanvohra34@gmail.com

'Department of Pharmaceutical Sciences and Drug Research, Punjabi

University, Patiala, India

Full list of author information is available at the end of the article
}

\section{Springer Open}

( ) The Author(s). 2020 Open Access This article is licensed under a Creative Commons Attribution 4.0 International License, which permits use, sharing, adaptation, distribution and reproduction in any medium or format, as long as you give appropriate credit to the original author(s) and the source, provide a link to the Creative Commons licence, and indicate if changes were made. The images or other third party material in this article are included in the article's Creative Commons licence, unless indicated otherwise in a credit line to the material. If material is not included in the article's Creative Commons licence and your intended use is not permitted by statutory regulation or exceeds the permitted use, you will need to obtain permission directly from the copyright holder. To view a copy of this licence, visit http://creativecommons.org/licenses/by/4.0/. 


\section{Background}

Hypertension globally accounts for 9.4 million deaths worldwide every year (WHO, 2015). Vascular inflammation plays a key role in the progression of essential hypertension [1]. Progranulin (PGRN), also known as granulin precursor 88/platelet cell (GP88/PC) derived factor, is a pleiotropic growth factor and one of the major anti-inflammatory molecules that plays an important part in the maintenance and regulation of the homeostatic dynamics in normal tissue development, proliferation, regeneration, and the host defense response [2]. PGRN is abundantly expressed in epithelial cells, immune cells, neurons and chondrocytes [3-5]. PGRN-mediated inhibition of tumor necrosis factoralpha (TNF- $\alpha$ ), a highly pleiotropic cytokine, activity has been well-established [6-8]. Serum PGRN levels has been estimated in various diseases which are characterized by presence of chronic low-grade inflammation such as atherosclerosis [9], neuro-degenerative diseases [10], breast cancer [11], diabetes [12], and metabolic syndrome [13]. Despite of the role of chronic inflammation in hypertension, novel anti-inflammatory marker serum PGRN levels and serum PGRN/TNF- $\alpha$ ratio had not been yet estimated in hypertensive patients and their association with systolic blood pressure (SBP) and diastolic blood pressure (DBP) is not explored.

\section{Methods}

A prospective, cross-sectional study was conducted in hypertensive patients. The study protocol was approved (approval number 263/DLS/HG) by human institutional ethics committee (IEC) of the academic institute and was performed in accordance with the code of Good Clinical Practice and followed STROBE guidelines for observational studies. All patients provided written informed consent to participate after a full explanation of the study. Hypertensive patients visiting the hospital for their regular checkup/ new diagnosis/or their ongoing treatment for hypertension (systolic-diastolic hypertension or isolated systolic hypertension) during a period of 8 months (March 2015 to October 2015) were assessed for eligibility (inclusion/exclusion) criteria of the study. Simple random sampling design was selected for inclusion of the subjects to exclude bias in selection of patients. Overall 80 patients were screened for hypertension and isolated systolic hypertension for eligibility criteria. Finally, 25 patients (age $\geq 18$ years) of isolated systolic hypertension (ISH), defined as $\mathrm{SBP} \geq 140 \mathrm{mmHg}$ and $\mathrm{DBP} \leq 90 \mathrm{~mm} \mathrm{Hg}$; and 25 patients of systolic-diastolic hypertension (SDH) defined as SBP $\geq$ $120 \mathrm{mmHg}$ and DBP $\geq 90 \mathrm{mmHg}$ according to the Eighth Joint National Committee (JNC)-VIII guidelines for hypertension [14] were recruited. Twenty-five age and body mass index (BMI)- matched healthy subjects were considered as control. Patients were excluded if having any other concomitant chronic inflammatory disease; history of type
1 and type 2 diabetes, continuous use of systemic steroids and NSAIDs; history of any concurrently present other major cardiovascular and metabolic disorders (congestive heart failure, stroke, ischemia, arrhythmia, dyslipidemia, thyroid disorders etc.); alcoholic and smokers; and pregnant and lactating women.

Clinical evaluations included the demographic profile and serum biomarkers. Overnight fasting blood samples of the patients and healthy subjects were withdrawn, serum was separated out and stored at $-40{ }^{\circ} \mathrm{C}$ till further analysis. The blood pressure was measured using manual mercurial sphygmomanometer on the same day just before withdrawing blood sample. Body mass index of subjects was calculated as weight in kilogram/square meter height [15]. Serum progranulin and TNF- $\alpha$ levels were measured using ELISA diagnostic kits (Krishgen Biosystems, India). Main outcome was to find serum PGRN level, TNF- $\alpha$ level, and the PGRN/TNF- $\alpha$ ratio to evaluate the pro- and anti-inflammatory environment of patients [16] and whether these can act as independent predictors of blood pressure.

Results were expressed as mean \pm standard deviation (SD). One-way analysis of variance (ANOVA) test was used to compare the variables between the groups. The correlation between various clinical variables was examined by Pearson's univariate correlation analysis. Multiple linear regression was used to reveal dependency of one variable on the other. All data were analyzed using Sigma Stat 3.5. Statistical significance was accepted at $p$ $\leq 0.05$.

Samples size was determined by considering serum progranulin level as primary marker for predicting blood pressure. Serum progranulin levels have been reported as $40.1 \pm 8.7 \mathrm{ng} / \mathrm{ml}$ in health subjects by Yamamoto et al. 2014 [16]. Based on this finding, 25\% elevated level of serum progranulin in hypertensives than healthy subjects were considered significant. Thus, to detect a difference of $25 \%$ at $95 \%$ power, a sample size of 25 subjects/group was required.

\section{Results}

The distribution of demographic, biochemical and hemodynamic characteristics are presented in Table 1. Figure 1 shows the flow chart of patients' inclusion in the study. All the eligible patients as per inclusion/exclusion criteria completed the study. There were no missing observations. Patients were on multiple anti-hypertensive drug therapies according to JNC-VIII guidelines for treatment of ISH and SDH [14]. More than 50\% of patients were on single anti-hypertensive drug therapy and approximately $10 \%$ were taking combination of three drugs. None of the patient included was newly diagnosed. All patients were confirmed and stable cases of ISH and their hypertension was controlled with medications at the time of recruitment. 
Table 1 Demographic, clinical, and biochemical characteristics of the subjects

\begin{tabular}{|c|c|c|c|c|}
\hline Parameters & $\begin{array}{l}\text { Group I } \\
\text { (control) } \\
(n=25)\end{array}$ & $\begin{array}{l}\text { Group II } \\
\text { (SDH patients) } \\
(n=25)\end{array}$ & $\begin{array}{l}\text { Group III } \\
\text { (ISH patients) } \\
(n=25)\end{array}$ & $p$ \\
\hline Male/female number & $11 / 14$ & $15 / 10$ & $12 / 13$ & \\
\hline AGE (years) & $56.00 \pm 8.55$ & $52.95 \pm 12.61$ & $55.80 \pm 9.40$ & 0.55 \\
\hline $\mathrm{BMI}\left(\mathrm{kg} / \mathrm{m}^{2}\right)$ & $25.35 \pm 6.92$ & $28.12 \pm 6.52$ & $27.37 \pm 5.32$ & 0.28 \\
\hline $\mathrm{SBP}(\mathrm{mmHg})$ & $121.36 \pm 5.15$ & $161.75 \pm 15.49$ & $168.68 \pm 7.17$ & $<0.001^{*}$ \\
\hline $\mathrm{DBP}(\mathrm{mmHg})$ & $82.36 \pm 3.63$ & $102.50 \pm 5.50$ & $89.20 \pm 2.55$ & $<0.001^{*}$ \\
\hline $\mathrm{PP}(\mathrm{mmHg})$ & $39.00 \pm 5.90$ & $59.25 \pm 13.40$ & $79.48 \pm 7.14$ & $<0.001^{*}$ \\
\hline Progranulin (ng/ml) & $50.10 \pm 4.70$ & $71.36 \pm 18.36$ & $82.31 \pm 16.32$ & $\begin{array}{l}<0.001^{*} \\
0.009 \wedge\end{array}$ \\
\hline TNF-a $(p g / m l)$ & $3.57 \pm 1.90$ & $19.68 \pm 5.19$ & $21.07 \pm 6.32$ & $\begin{array}{l}<0.001^{*} \\
0.31 \wedge\end{array}$ \\
\hline PGRN/TNF-a ratio & $23.98 \pm 7.44$ & $3.79 \pm 1.33$ & $4.32 \pm 1.80$ & $\begin{array}{l}<0.01^{*} \\
0.67 \wedge\end{array}$ \\
\hline
\end{tabular}

$B M I$ body mass index, SBP systolic blood pressure, $D B P$ diastolic blood pressure, TNF- $a$ tumor necrosis factor alpha, $P G R N$ progranulin. Results are expressed as mean $\pm \mathrm{SD} ; p$ significant at $<0.05\left({ }^{*} p\right.$ value: patients vs. control; $\wedge p$ value $\mathrm{SDH}$ patients vs. ISH patients)

Age and disease duration ranged from 30 to 62 years, duration 3-20 months; age 39-72 years, duration 3-12 months in SDH and ISH patients, respectively.

On comparing the groups, age and BMI of healthy and patients were not significantly different (all $p>$ $0.05)$. Since the sample size was very less, patients' data was not subcategorized on the basis of age, sex, and BMI. All the patients and healthy subjects were overweight (average BMI, 25-29.9 $\mathrm{kg} / \mathrm{m}^{2}$ ), but none was having dyslipidemia and on any weight reduction/hypolipidemic treatment. In this study, low TNF- $\alpha$ levels and high PGRN levels in healthy subjects revealed absence of low-grade inflammation and a balance between endogenous pro- and anti-inflammatory cytokines. Both progranulin and TNF- $\alpha$ levels were found high in SDH and ISH patients as compared to healthy subjects. High TNF- $\alpha$ levels depict the presence of low-grade inflammation in hypertension. Elevated PGRN levels in response to raised TNF- $\alpha$ levels depicts the counter regulation by PGRN to neutralize TNF- $\alpha$. Moreover, PGRN/TNF- $\alpha$ ratio was found significantly decreased in ISH and $\mathrm{SDH}$ patients as compared to healthy subjects.

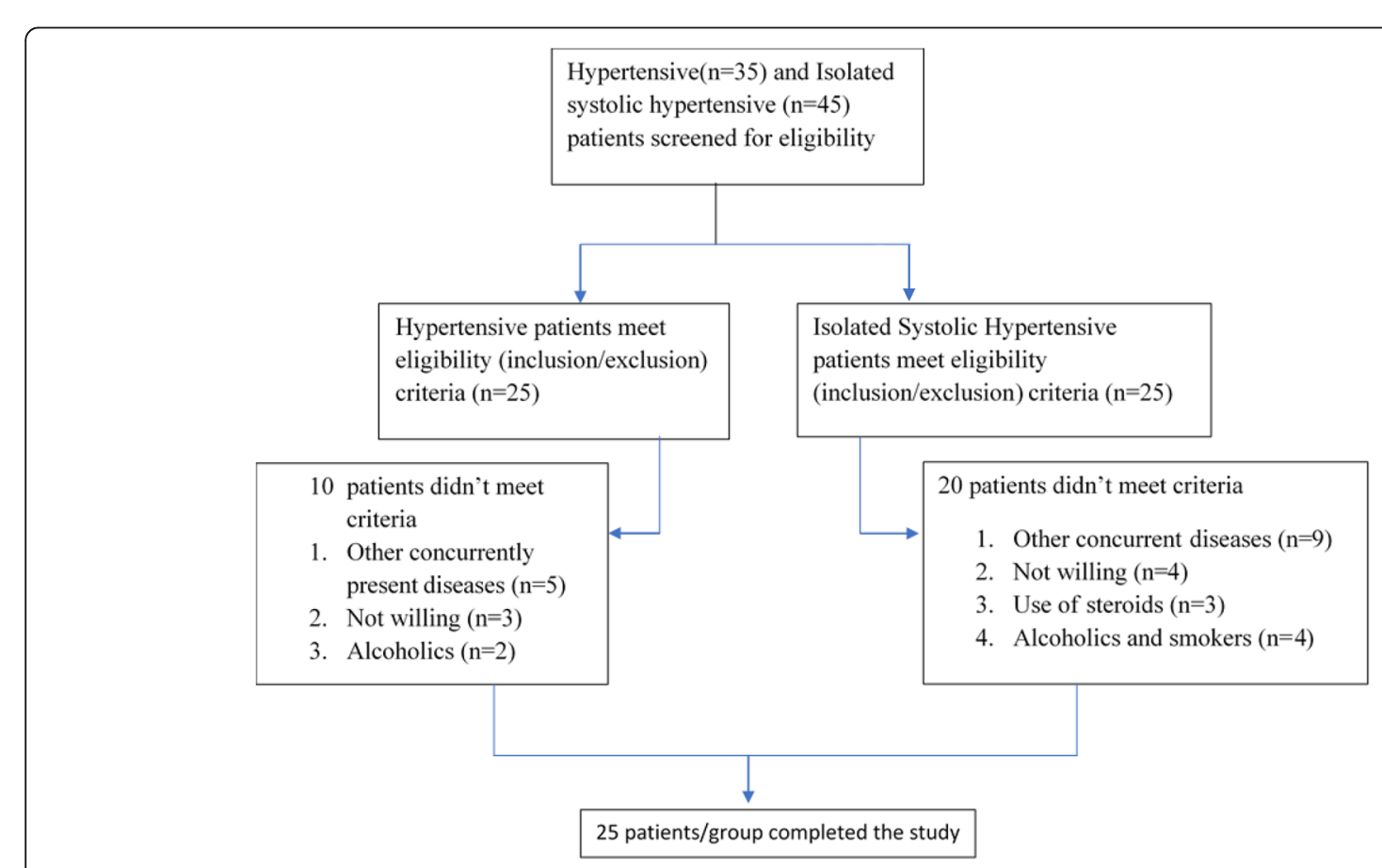

Fig. 1 Selection criteria of study participants 
Among all variables in ISH patients, age was significantly associated with SBP $(r=0.42, p=0.04)$ and PP $(r$ $=0.43, p=0.03)$; SBP with PGRN $(r=0.44, p=0.03)$ and PP $(r=0.98, p<0.01)$; PGRN/TNF- $\alpha$ ratio with PGRN $(r=0.59, p=0.02)$, TNF- $\alpha(r=-0.79, p<0.01)$, and PP $(r=0.42, p=0.04)$.

Among all variables in SDH patients, both age and BMI were not significantly correlated with any parameter like SBP, DBP, PP, PGRN, and TNF- $\alpha$. SBP was correlated with $\mathrm{PP}(r=0.93, p<0.01)$, DBP $(r=0.53, p=$ $0.01)$, PGRN $(r=0.49, p=0.02)$, and TNF- $\alpha(r=0.46, p$ $=0.03)$; PP with TNF- $\alpha(r=0.51, p=0.02)$ and PGRN $(r$ $=0.50, p=0.02)$. PGRN $/$ TNF $-\alpha$ ratio $(r=0.59, p=0.04)$ with PGRN $(r=0.59, p=0.04)$ and TNF- $\alpha(r=-0.61, p$ $=0.03)$. No other significant association was found between remaining variables (all $p>0.05$ ).

Independent and linear predictors of SBP were determined using multiple linear regression analysis. Variables which showed significant correlation with SBP were entered into multiple linear regression model to find independent predictors of SBP. Only PGRN/TNF- $\alpha$ ratio and $\mathrm{PP}$ were found as independent predictors of SBP both in $\mathrm{SDH}$ and ISH patients after adjustment of age, sex, BMI, and DBP (Table 2).

\section{Discussion}

Low-grade inflammation imparts a crucial pathogenic role in systolic-diastolic hypertension and isolated systolic hypertension. This study had revealed an imbalance between pro-inflammatory cytokine (TNF- $\alpha$ ) and antiinflammatory growth factor (PGRN) in hypertensive patients. Reduced PGRN/TNF- $\alpha$ ratio further supports the inflammatory basis of the disease. Moreover, PGRN/ TNF ratio was also found as independent predictor of SBP that ascertain the significance of inflammatory component responsible for increasing SBP.

ISH is the most common form of hypertension in those older than 65 years [17]. Lloyd-Jones et al. 2000 revealed that increasing age was significantly associated with lack of SBP control [18]. Similarly, Midha et al.

Table 2 Independent predictors of SBP

\begin{tabular}{|c|c|c|c|c|}
\hline S. no. & Parameters & B & $T$ & $p^{*}$ \\
\hline \multicolumn{5}{|c|}{ Independent predictors of SBP in SDH patients } \\
\hline 1 & PGRN/TNF-a & 0.74 & 6.58 & $<0.01$ \\
\hline \multirow[t]{2}{*}{2} & PP & 0.85 & 4.7 & 0.03 \\
\hline & & \multicolumn{3}{|c|}{$\mathrm{SBP}=5.68+(2.023 \times \mathrm{PGRN} / \mathrm{TNF})+(0.56 \times \mathrm{PP})$} \\
\hline \multicolumn{5}{|c|}{ Independent predictors of SBP in ISH patients } \\
\hline 1 & PGRN/TNF-a & 0.73 & 2.08 & 0.05 \\
\hline \multirow[t]{2}{*}{2} & $\mathrm{PP}$ & 0.89 & 22.82 & $<0.01$ \\
\hline & & \multicolumn{3}{|c|}{$\mathrm{SBP}=93.65+(0.73 \times \mathrm{PGRN} / \mathrm{TNF})+(0.89 \times \mathrm{PP})$} \\
\hline
\end{tabular}

$P G R N$ progranulin, $T N F-a$ tumor necrosis factor-alpha, $P P$ pulse pressure ${ }^{*} p<0.05$ statistically significant
2010 found that age, BMI and smoking were significant independent risk factors of ISH [19]. Martins et al. 2002 also demonstrated an inverse relation between BMI and PP among lean versus obese subjects with ISH [20]. In the present study, age was found significantly associated with SBP in ISH patients, but BMI was not correlated with SBP neither in ISH nor in SDH patients.

TNF- $\alpha$ is considered a potent pro-inflammatory cytokine which plays a crucial role in the initiation and continuation of inflammation and immunity. Various studies have shown raised levels of TNF- $\alpha$ in cardio-vascular diseases characterized by presence of low-grade inflammation including obesity [21], diabetes [22], metabolic syndrome [23], and atherosclerosis [24]. Present study too has shown raised serum levels of TNF- $\alpha$, revealing the low-grade inflammation as an inherent feature of ISH.

PGRN acts as a strong anti-inflammatory mediator by antagonizing TNF- $\alpha$ signaling. The anti-inflammatory effects of PGRN are exerted through inhibition of TNF receptor (TNFR)-mediated nuclear factor- $\mathrm{kB}$ (NF-kB) and mitogen-activated protein kinase (MAPK) signaling by competitively binding to TNFR, especially TNFR-2, which is found in bone marrow derived macrophages [25]. Many clinical studies have reported adverse levels of circulating PGRN in many diseases characterized by presence of low-grade inflammation, including metabolic syndrome [9], diabetes mellitus [26, 27], renal dysfunction [13], and atherosclerosis [28]. Xu et al. $2015 \mathrm{had}$ found a marked positive correlation between serum PGRN levels with SBP and DBP in diabetic patients having microangiopathies [26]. Present study had also found raised PGRN levels in hypertensive patients than healthy subjects, and as well had revealed an association with PP.

Given that PGRN acts as a strong anti-inflammatory mediator by antagonizing TNF- $\alpha$ signaling, we further investigated the relationship between serum PGRN levels and TNF- $\alpha$ levels in patients with ISH. We found that serum PGRN levels increased with the rising of TNF- $\alpha$ levels. Based on these results, we speculated that PGRN, as a competitive molecule of TNF- $\alpha$, is highly expressed in hypertension secondary to the increased inflammatory cytokines, particularly, TNF- $\alpha$. We speculated that the ratio of PGRN/TNF- $\alpha$ in serum is an important factor to evaluate the inflammatory microenvironment of patient. The findings of low PGRN/TNF ratio in hypertensives as compared to healthy subjects depicted the feedback control/regulation of TNF- $\alpha$ by PGRN. To confirm this speculation, we studied the relationship between serum PGRN/TNF- $\alpha$ ratio and SBP and found that serum PGRN/TNF- $\alpha$ ratio was an independent predictor of SBP. These results create a link between the concept of immunity-inflammation-blood pressure, a sequential and vicious network. 
Present study had several limitations such as small sample size, a few numbers of variables, not measured serum soluble TNF receptor 1 (TNFR1) and TNFR2 level, no differentiation of results based on age, gender, smoking, disease severity, and other risk factors/or concomitantly present diseases. The results are based on evaluation of few patients and healthy subjects which may not justify the findings based on low statistical power of the study. In many published studies, blood pressure is taken as one of the co-variables with other main variables for observing association of serum PGRN with the disease profile. This is the first study reporting the correlation of serum PGRN/TNF ratio in systolic hypertensives in comparison to systolic-diastolic hypertensive subjects. Although results may not be robust enough but provide a preliminary data for futuristic clinical studies in hypertensive patients.

\section{Conclusion}

The findings of reduced PGRN/TNF ratio as an independent predictor of SBP, ascertain the key role of imbalance in pro- and anti-inflammatory environment in hypertension. Thus, it strengthens the link between the concept of immunity-adiposity-inflammation-blood pressure, a sequential and vicious network. As PGRN is widely explored anti-inflammatory marker in various diseases, its serum levels and correlation status must be further explored with regard to age, sex, BMI, duration of hypertension, various stages, severity, and types of hypertension, as well as presence of other pro-/anti-inflammatory markers and concomitant cardiovascular disease risk variables. Further, this cross-link of SBP and progranulin must be explored in longitudinal studies to generalize the findings. New Researches should be focused not only on impact of pro-inflammatory environment rather to find on a balance between pro- and anti-inflammatory status, so that new target sites could be explored for therapeutic management of hypertension.

\section{Abbreviations}

PGRN: Progranulin; TNF-a: Tumor necrosis factor-alpha; PP: Pulse pressure; SDH: Systolic-diastolic hypertension; ISH: Isolated systolic hypertension; BMI: Body mass index

\section{Acknowledgements}

We gratefully acknowledge academic contribution of Ms. Manpreet Kaur, Research Scholar, Department of Pharmaceutical Sciences and Drug Research, Punjabi University, Patiala, in preparing the manuscript.

\section{Authors' contributions}

This work was carried out in collaboration between all authors. Author JK and SM carried out experimental work, wrote the first draft of the manuscript, and managed the literature searches under the supervision of author KV and co-authors SV and BSK. Authors KV, SV, and BSK did final editing of the manuscript. Author HK helped in literature retrieval and data analysis. All authors have read and approved the final manuscript.

\section{Funding}

There was no external funding source. The academic institute Punjabi University, Patiala, provided all the necessary funds to the research scholar(s) for completing their dissertation work.

\section{Availability of data and materials}

The datasets used and/or analyzed during the current study are available from the corresponding author on reasonable request. All data generated or analyzed during this study are included in this published article.

\section{Ethics approval and consent to participate}

The study protocol was approved (approval number 263/DLS/HG) by Human Institutional Ethics Committee (IEC) of Punjabi University, Patiala, and was performed in accordance with the Declaration of Helsinki and the code of Good Clinical Practice. All patients provided written informed consent to participate after a full explanation of the study.

\section{Consent for publication}

Not applicable

\section{Competing interests}

The authors declare that they have no competing interests.

\section{Author details}

${ }^{1}$ Department of Pharmaceutical Sciences and Drug Research, Punjabi University, Patiala, India. ²Sadbhavna Medical \& Heart Institute, Patiala, India. ${ }^{3}$ A. P. Jain Civil Hospital, Rajpura, Patiala, India.

Received: 30 January 2020 Accepted: 3 May 2020

Published online: 18 May 2020

\section{References}

1. Virdis A, Dell'Agnello U, Taddei S (2014) Impact of inflammation on vascular disease in hypertension. Maturitas 78(3):179-183

2. Zhou J, Gao GU, Crabb JW, Serrero G (1993) Purification of an autocrine growth factor homologous with mouse epithelin precursor from a highly tumorigenic cell line. J Biol Chem 268(15):10863-10869

3. Xu K, Zhang Y, llalov K, Carlson CS, Feng JQ, Di Cesare PE, Liu CJ (2007) Cartilage oligomeric matrix protein associates with granulin-epithelin precursor (GEP) and potentiates GEP-stimulated chondrocyte proliferation. J Biol Chem 282(15):11347-11355

4. Feng JQ, Guo FJ, Jiang BC, Zhang Y, Frenkel S, Wang DW, Tang W, Xie Y, Liu CJ (2010) Granulin epithelin precursor: a bone morphogenic protein 2inducible growth factor that activates Erk1/2 signaling and JunB transcription factor in chondrogenesis. FASEB J 24(6):1879-1892

5. Guo F, Lai Y, Tian Q, Lin EA, Kong L, Liu C (2010) Granulin-epithelin precursor binds directly to ADAMTS-7 and ADAMTS-12 and inhibits their degradation of cartilage oligomeric matrix protein. Arthritis Rheum 62(7): 2023-2036

6. Guo Z, Li Q, Han Y, Liang Y, Xu Z, Ren T (2012) Prevention of LPS-induced acute lung injury in mice by progranulin. Mediat Inflamm 2012:540794

7. Egashira Y, Suzuki Y, Azuma Y, Takagi T, Mishiro K, Sugitani S, Tsuruma K Shimazawa M, Yoshimura S, Kashimata M, Iwama T (2013) The growth factor progranulin attenuates neuronal injury induced by cerebral ischemiareperfusion through the suppression of neutrophil recruitment. J Neuro Inflamm 10(1):884

8. Kawase R, Ohama T, Matsuyama A, Matsuwaki T, Okada T, Yamashita T, Yuasa-Kawase M, Nakaoka H, Nakatani K, Inagaki M, Tsubakio-Yamamoto K (2013) Deletion of progranulin exacerbates atherosclerosis in ApoE knockout mice. Cardiovasc Res 100(1):125-133

9. Yoo HJ, Hwang SY, Hong HC, Choi HY, Yang SJ, Choi DS, Baik SH, Blüher M, Youn BS, Choi KM (2013) Implication of progranulin and C1q/TNF-related protein-3 (CTRP3) on inflammation and atherosclerosis in subjects with or without metabolic syndrome. PLoS One 8(2):e55744

10. Sleegers K, Brouwers N, Van Damme P, Engelborghs S, Gijselinck I, van der Zee J, Peeters K, Mattheijssens M, Cruts M, Vandenberghe R, De Deyn PP (2009) Serum biomarker for progranulin-associated frontotemporal lobar degeneration. Ann Neurol 65(5):603-609

11. Lu R, Serrero G (2000) Inhibition of PC cell-derived growth factor (PCDGF, epithelin/granulin precursor) expression by antisense PCDGF CDNA 
transfection inhibits tumorigenicity of the human breast carcinoma cell line MDA-MB-468. Proc Natl Acad Sci 97(8):3993-3998

12. Youn BS, Bang SI, Klöting N, Park JW, Lee N, Oh JE, Pi KB, Lee TH, Ruschke K, Fasshauer M, Stumvoll M (2009) Serum progranulin concentrations may be associated with macrophage infiltration into omental adipose tissue. Diabetes 58(3):627-636

13. Richter J, Focke D, Ebert T, Kovacs P, Bachmann A, Lössner U, Kralisch S, Kratzsch J, Beige J, Anders M, Bast I (2013) Serum levels of the adipokine progranulin depend on renal function. Diabetes Care 36(2):410-414

14. James PA, Oparil S, Carter BL, Cushman WC, Dennison-Himmelfarb C, Handler J, Lackland DT, LeFevre ML, MacKenzie TD, Ogedegbe O, Smith SC (2014) 2014 evidence-based guideline for the management of high blood pressure in adults: report from the panel members appointed to the Eighth Joint National Committee (JNC 8). JAMA 311(5):507-520

15. Mei Z, Grummer-Strawn LM, Pietrobelli A, Goulding A, Goran MI, Dietz WH (2002) Validity of body mass index compared with other body-composition screening indexes for the assessment of body fatness in children and adolescents. Am J Clin Nutr 75(6):978-985

16. Yamamoto $Y$, Takemura M, Serrero G, Hayashi J, Yue B, Tsuboi A, Kubo H, Mitsuhashi T, Mannami K, Sato M, Matsunami H (2014) Increased serum GP88 (Progranulin) concentrations in rheumatoid arthritis. Inflammation 37(5):1806-1813

17. Kaplan NM (2000) New issues in the treatment of isolated systolic hypertension. Circulation 102:1079-1081

18. Lloyd-Jones DM, Evans JC, Larson MG, O'Donnell CJ, Roccella EJ, Levy D (2000) Differential control of systolic and diastolic blood pressure: factors associated with lack of blood pressure control in the community. Hypertension 36(4):594-599

19. Midha T, Idris MZ, Saran RK, Srivastava AK, Singh SK (2010) Isolated systolic hypertension and its determinants-A cross-sectional study in the adult population of Lucknow district in North India. Indian J Community Med 35(1):89

20. Martin D, Tareen N, Pan D, Norris K (2002) The relationship between body mass index and pulse pressure in older adults with isolated systolic hypertension. Am J Hypertens 15(6):538-543

21. Maachi M, Pieroni L, Bruckert E, Jardel C, Fellahi S, Hainque B, Capeau J, Bastard JP (2004) Systemic low-grade inflammation is related to both circulating and adipose tissue TNFa, leptin and IL-6 levels in obese women. Int J Obes 28(8):993-997

22. Van Greevenbroek MM, Schalkwijk CG, Stehouwer CD (2013) Obesityassociated low-grade inflammation in type 2 diabetes mellitus: causes and consequences. Neth J Med 71(4):174-187

23. Gupta V, Gupta A, Jafar T, Gupta V, Agrawal S, Srivastava N, Kumar S, Singh AK, Natu SM, Agarwal CG, Agarwal GG (2012) Association of TNF-a promoter gene G-308A polymorphism with metabolic syndrome, insulin resistance, serum TNF-a and leptin levels in Indian adult women. Cytokine 57(1):32-36

24. Olson NC, Callas PW, Hanley AJ, Festa A, Haffner SM, Wagenknecht LE, Tracy RP (2012) Circulating levels of TNF-a are associated with impaired glucose tolerance, increased insulin resistance, and ethnicity: The Insulin Resistance Atherosclerosis Study. J Clin Endocrinol Metab 97(3):1032-1040

25. Tang W, Lu Y, Tian QY, Zhang Y, Guo FJ, Liu GY, Syed NM, Lai Y, Lin EA, Kong L, Su J (2011) The growth factor progranulin binds to TNF receptors and is therapeutic against inflammatory arthritis in mice. Science 332(6028): 478-484

26. Xu L, Zhou B, Li H, Liu J, Du J, Zang W, Wu S, Sun H (2015) Serum levels of progranulin are closely associated with microvascular complication in type 2 diabetes. Dis Markers 2015:2015. https://doi.org/10.1155/2015/357279

27. Qu H, Deng H, Hu Z (2013) Plasma Progranulin Concentrations Are Increased in Patients with Type 2 Diabetes and Obesity and Correlated with Insulin Resistance. Mediat Inflamm 2013:360190

28. Kojima Y, Ono K, Inoue K, Takagi Y, Kikuta Kl, Nishimura M, Yoshida Y, Nakashima Y, Matsumae H, Furukawa Y, Mikuni N (2009) Progranulin expression in advanced human atherosclerotic plaque. Atherosclerosis 206(1):102-108

\section{Publisher's Note}

Springer Nature remains neutral with regard to jurisdictional claims in published maps and institutional affiliations.

\section{Submit your manuscript to a SpringerOpen ${ }^{\circ}$ journal and benefit from:}

- Convenient online submission

- Rigorous peer review

- Open access: articles freely available online

- High visibility within the field

- Retaining the copyright to your article

Submit your next manuscript at $\boldsymbol{\nabla}$ springeropen.com 